The Canadian Mineralogist

Vol. 43, pp. 543-552 (2005)

\title{
THE OPTICAL ANALYSIS OF MINERALS
}

\author{
DAVID K. TEERTSTRA ${ }^{\S}$ \\ Euclid Geometrics, 843 Queens Boulevard, Kitchener, Ontario N2M 1A6, Canada
}

\begin{abstract}
Optical analysis combines the measurements of index of refraction $(n)$ and density $(D)$ to closely constrain the structural formula and hence to provide an independent check on composition. Physically, light of specific energy is refracted to a unique degree by each element, so that each photon follows the bonds through the structure of the mineral. The ionic refractivity generally increases with atomic number and is modified by the electrical environment of the bond at each crystallographic site. In general, $n$ changes in proportion to $D$, such that $n \propto D$ and $K=n / D$ for each mineral composition. From the change $\Delta n / \Delta \mathrm{D}$ of specific mechanisms of substitution, the per-ion contribution $(i)$ to $n$ and $D$ are found with $K=\Sigma\left(k_{\mathrm{i}} d_{\mathrm{i}}\right)$, where $k_{\mathrm{i}}$ is the ionic refractivity and $d_{\mathrm{i}}$ is the fractional density. The absolute contribution to density by an ion in the unit-cell volume is $\left|d_{\mathrm{i}}\right|=m_{\mathrm{i}} / V_{\text {cell }}$ $=w_{\mathrm{i}} D$, with $D=\Sigma m_{\mathrm{i}} / V_{\text {cell }}$. The fractional density $d_{\mathrm{i}}$ equals the weight fraction of the ion, $d_{\mathrm{i}}=w_{\mathrm{i}}=a_{\mathrm{i}} \mathrm{AW} / \mathrm{FW}$, in which each ion $\left(a_{\mathrm{i}}\right)$ of atomic weight (AW) contributes to the formula weight $(\mathrm{FW})$. The absolute contribution of the refractivity of Fe to $n_{\text {almandine }}$ is $\left|n_{\mathrm{Fe}}\right|=k_{\mathrm{Fe}}\left|d_{\mathrm{Fe}}\right|$. The number of atoms per formula unit in $\left(\mathrm{Fe}_{2} \mathrm{Mg}\right) \mathrm{Al}_{2} \mathrm{Si}_{3} \mathrm{O}_{12}$ is indicated by $K=\left[k\left(\mathrm{Fe}^{2+}\right)\left(2 \mathrm{AW}_{\mathrm{Fe}}\right)+\right.$ $\left.k\left(\mathrm{Mg}^{2+}\right)\left(\mathrm{AW}_{\mathrm{Mg}}\right)+k\left(\mathrm{Al}^{3+}\right)\left(2 \mathrm{AW}_{\mathrm{Al}}\right)+k\left(\mathrm{Si}^{4+}\right)(3 \mathrm{AW} \mathrm{Si})+k\left(\mathrm{O}^{2-}\right)\left(12 \mathrm{AW}_{\mathrm{O}}\right)\right] / \mathrm{FW}$. A solved set of $k_{\mathrm{i}}$ values yields the weight fractions of ions and the structural formula from the measured index of refraction and unit-cell edge or density.
\end{abstract}

Keywords: index of refraction, polarized light, optical mineralogy, photon, Gladstone-Dale relation, mineral composition, garnet.

\section{SOMMAIRE}

Une analyse optique repose sur des mesures de l'indice de réfraction $(n)$ et de la densité $(D)$ afin de mieux délimiter la formule structurale, et ainsi fournir une vérification indépendante de la composition. En termes physiques, une lumière ayant une énergie spécifique est réfractée de manière unique par chaque élément, de sorte que chaque photon longe les liaisons en traversant la structure du minéral. La réfractivité ionique augmente généralement avec le nombre atomique et se trouve modifiée par le milieu électrique de la liaison à chaque site cristallographique. En général, $n$ change en proportion à $D$, de sorte que $n$ ä $D$, et $K=n / D$ pour chaque composition d'un minéral. En partant du changement $\Delta n / \Delta \mathrm{D}$ dû aux mécanismes spécifiques de substitution, la contribution spécifique d'un ion $(i)$ à $n$ et à $D$ découlent de $K=\Sigma\left(k_{\mathrm{i}} d_{\mathrm{i}}\right)$, expression dans laquelle $k_{\mathrm{i}}$ est la réfractivité ionique, et $d_{\mathrm{i}}$ est la contribution fractionelle à la densité. La contribution absolue à la densité par un ion dans le volume d'une maille élémentaire est $\left|d_{\mathrm{i}}\right|=m_{\mathrm{i}} / V_{\text {maille }}=w_{\mathrm{i}} D$, avec $D=\sum m_{\mathrm{i}} / V_{\text {maille. }}$. La densité fractionnelle $d_{\mathrm{i}}$ est égale à la fraction pondérale d'un ion, $d_{\mathrm{i}}=w_{\mathrm{i}}=a_{\mathrm{i}} \mathrm{AW} /$ $\mathrm{FW}$, dans laquelle chaque ion $\left(a_{\mathrm{i}}\right)$ ayant un poids atomique (AW) contribue au poids formulaire (FW). La contribution absolue de la réfractivité de $\mathrm{Fe}$ à $n_{\text {almandine }}$ serait $\left|n_{\mathrm{Fe}}\right|=k_{\mathrm{Fe}}\left|d_{\mathrm{Fe}}\right|$. Le nombre d'atomes dans une unité formulaire de $\left(\mathrm{Fe}_{2} \mathrm{Mg}\right) \mathrm{Al}_{2} \mathrm{Si}_{3} \mathrm{O}_{12}$ est révélé par $K=\left[k\left(\mathrm{Fe}^{2+}\right)\left(2 \mathrm{AW}_{\mathrm{Fe}}\right)+k\left(\mathrm{Mg}^{2+}\right)\left(\mathrm{AW}_{\mathrm{Mg}}\right)+k\left(\mathrm{Al}^{3+}\right)\left(2 \mathrm{AW}_{\mathrm{Al}}\right)+k\left(\mathrm{Si}^{4+}\right)\left(3 \mathrm{AW}_{\mathrm{Si}}\right)+k\left(\mathrm{O}^{2-}\right)(12 \mathrm{AW} \mathrm{O})\right] / \mathrm{FW}$. Une liste de valeurs affinées de $k_{\mathrm{i}}$ mène aux fractions pondérales des ions et à la formule structurale à partir de l'indice de réfraction mesuré et le paramètre réticulaire ou la densité.

(Traduit par la Rédaction)

Mots-clés: indice de réfraction, lumière polarisée, minéralogie optique, photon, relation de Gladstone et Dale, composition minérale, grenat.

$\S \quad$ E-mail address: en369@ncf.ca 


\section{INTRODUCTION}

Mineralogists can identify many minerals on sight, from the optical characteristics of the bulk material. They commonly follow this with measurement of the index of refraction and density to confirm mineral identity or to estimate composition. With additional examination using plane-polarized-light microscopy, many more species can be distinguished with minimal ambiguity. Optical properties are also sensitive indicators of structure; thus variation of symmetry may be recognized optically even if the single-crystal structural results remain ambiguous. If a mineral exhibits unusual optical characteristics, a phase transition or structural change may be suspected, or an unusual composition may exist. The method of optical analysis requires that the index of refraction, unit-cell and density data be consistent with the composition indicated by the structural formula, thus constraining the valence of ions and the state of order.

Most analytical methods do not include provision for oxygen. Routine analysis by electron microprobe cannot deal with the light elements $\mathrm{H}, \mathrm{Li}, \mathrm{Be}, \mathrm{B}, \mathrm{C}, \mathrm{N}$ and $\mathrm{O}$. Consequently, as oxygen typically accounts for half the formula weight, the estimate of oxygen content by charge balance with the cations represents an accepted, but questionable, practice. Such typically incomplete analytical results, valence uncertainties and the possibility of variable distribution of cations among sites render the structural formula of many minerals ambiguous. But oxygen accounts for most of the volume of a mineral and contributes significantly to the index of refraction and density (as can the light elements from $\mathrm{H}$ to $\mathrm{N}$ ). Therefore, it is important to develop relations involving index of refraction, density and composition that constrain the structural formula of a mineral.

\section{BACKGROUND INFORMATION}

Close relations among index of refraction $(n)$, density $(D)$ and composition indicate the feasibility of quantitative optical analysis. However, empirically determined curves of $n-D$ - composition are accurate only in the simplest cases, mainly for pure minerals with limited compositional variability. For complex solidsolutions, the relation proposed by Gladstone and Dale (1864) attributes a specific refraction $\left(k_{\mathrm{o}}\right)$ to each oxide component. Then, average $k_{\mathrm{o}}$ values determined from minerals are used to verify the composition of new species. However, the mathematical and physical basis of determining $k_{\mathrm{o}}$ values has never been described. A quantitative atomistic explanation of the $n-D$ relation for bulk materials has not been developed, and refractedlight optical analysis remains at present an unsatisfactory secondary method of analysis.

By contrast, single-crystal structure refinement is accepted as a primary method of analysis. Using Bragg's law for reflected X-ray light, the distance between adjacent planes of atoms in a crystal is determined by the wavelength of X-ray photons, electrons or neutrons, by reflection at a certain angles. As the intensity of a reflection is proportional to the atomic number, composition is refined along with the crystal structure. Inclusion of a bond-valence analysis and a refinement of site occupancy using ionic scattering factors makes a singlecrystal refinement of a structure a valid primary method of compositional analysis. Furthermore, the light emitted or absorbed by a specific atomic transition is characteristic of an element. The radiated intensity is directly proportional to the ion concentration; conversely, Beer's law is applied for absorption, providing a basis for numerous analytical spectroscopic methods, and proton, ion and electron microprobes.

\section{THEORY OF REFRACTION}

In the theory of light as a wave, the reduction in velocity (from $\mathrm{c}$ to $v$ ) as light passes from vacuum into a mineral requires reduction of wavelength $(\lambda)$. In the wave equation, $v=f \lambda$, the frequency $f$ is the constant of proportionality. Note that the velocity $v$ is measured along an assumed linear path between entry and exit points. This is a simplification of ray optics wherein the refraction of a collimated beam of light is depicted as showing a sharp and immediate change of direction at a surface. A continuous beam is "bent" by refraction. In the Snell equation, the index of refraction is $n=c / v=$ $\sin (i) / \sin (r)$; the beam enters the material at angle $i$ and refracts at angle $r$ toward the normal. The wave mechanism of propagation is light-induced oscillation of the electrons of the material, such that the outer electrons of an atom are affected more by low-energy visible light than are its tightly bound inner electrons. This mechanism explains the greater degree of refraction from red to violet light, but contradicts wave theory.

The Snell equation indicates that a single mechanism causes both the change of direction and the net reduction of velocity. Light must change direction gradually as it enters the electric field-gradient of an ion; the ion charge density increases toward the nucleus (Fig. 1). At an atomic scale, light must refract along a curved path, but then there is no need for reduced velocity. Furthermore, identifying a specific refraction of ions means that light must change direction to a unique degree characteristic of each ion. But light refracting by inducing oscillation in the outer electrons of ions cannot follow a straight-line path through a mineral because the ions are in staggered array. Consistency with the Snell equation is possible only if light refracts continuously about both the surface and the interior atoms of a material, such that the length of the winding optical path $(l)$ is related to the length of the linear geometric path $(d)$ by $l=n d$; this relationship requires a particulate photon of constant velocity and wavelength, however. 


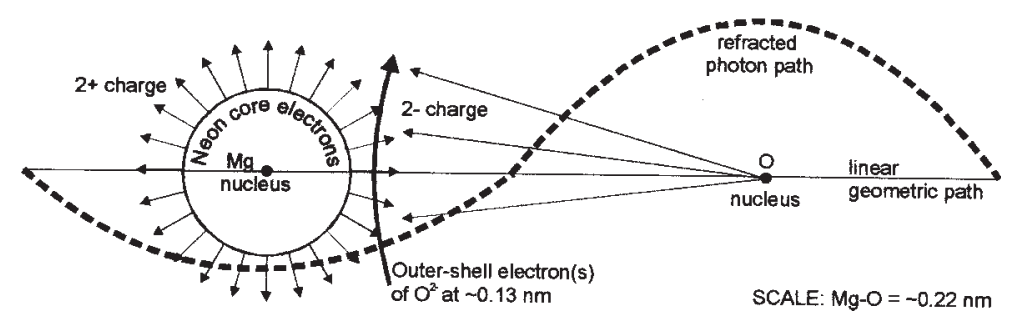

FIG. 1. Schematic refracted path of a photon through the $\mathrm{Mg}-\mathrm{O}$ bond. Two units of positive charge extend from the noble gas core of the cation. The valence electrons of oxygen (orbitals indicated by a solid line with an arrow) partly satisfy both the charge of its $\mathrm{O}$ nucleus and that of adjacent $\mathrm{Mg}^{2+}$. The refractive power of each ion is increased by the mutual overlap of opposite charges. As the photon takes a characteristic path about each ion (dashed line), the composition and structure may be refined.

A proposal of invariant velocity and wavelength is consistent with the quantum hypothesis of light as a stream of particles, each with energy $E=h f$, where $h$ is the Planck constant. Natural continuous oscillators that constantly lose energy by radiating a continuous wave of light remain unidentified, but rather a single photon is produced by a single atomic electrical transition to propagate as a finite local particle. Einstein argued that if an individual atom or electron absorbs a single packet of light, it is likely that light consists of small particles (Arons \& Peppard 1965, Teertstra 2003). The Maxwell theory of light (Iksander 1992) as an electromagnetic wave with energy spread over space requires a homogeneous refracting medium (formed by wave addition), so that light interacts with tens of thousands of atoms at the same time, whereas the Gladstone-Dale relation indicates that light is refracted to a specific degree by each component of a material. Each ion must maintain its characteristic electrical atomic structure. By the 1920s, the idea that each ion maintains local identity was supported by crystal-structure solutions using X-ray-diffraction data. With this method, the characteristic electron-density and radius of atoms at specific sites could be determined. In other words, a crystal is not a homogeneous refracting material.

Einstein (1905, from Arons \& Peppard 1965) also maintained relativistic invariance of the charges, so that the electrical charge of proton and electron remains constant, whereas the electrical binding energy E relates to change of rest mass by $m=E / c^{2}$. In this manner, charge is maintained as two ions bind to one another, whereas a reduction of electrical potential would weaken a bond, and reduction of rest mass is a means of describing the stability of materials. Refraction is thus not directly affected by inertial atomic mass, but each atom has a specific contribution of electrical charge and atomic mass, giving the unit-cell volume and density of a mineral, respectively.

Separate descriptions of light as wave and particle are merged by the hypothesis that electromagnetic en- ergy is in local oscillatory exchange with mass. A waveparticle unified model of the photon has been proposed in which refraction occurs by local entropic mechanisms (Teertstra 2003). A reasonable explanation of the index of refraction emerges with the proposal that light of specific energy refracts to a unique degree about each element, so that each photon winds through a mineral structure at a specific energy-level. In this case, it will be feasible to refine the composition of a mineral and retrieve structural information from the observed indices of refraction and data on density for the mineral group.

\section{Relating Index of Refraction and Density}

It is a $17^{\text {th }}$ century idea that optical density and gravitational density are related. Isaac Newton considered light as stream of particles refracting in the space between atoms (Baierlein 1992). The mineralogical literature contains a wealth of data supporting the idea that each element contributes its unique refractive and atomic-weight properties to the net index of refraction and bulk density. Across numerous solid-solution series, both index of refraction and unit-cell parameters vary in a linear manner for compositions plotted on the basis of atoms per formula unit $(a p f u)$. Across composition space, lines of constant $n$ are typically equally spaced, as are curves of constant $D$; garnet-group minerals provide an example. Unique intersections of $n$ and $D$ indicate the possibility of identifying a unique composition by comparison of states across compositional space, via optical analysis. In contrast to glass, the change in $n$ and $D$ across mineral series is related to variable composition by specific mechanism(s) of substitution defined at crystallographic sites. The unit-cell volume can be explained by characteristic ionic radii (Novak \& Gibbs 1971), and the density can be explained by atomic weights. Now, the refraction can be explained by the specific ionic refractivity. 
In the example of garnet-group minerals, linear covariation of $n$ and cell edge $a$ is found along each exchange vector. Linear relations are also found in plots of $n$ or $a$ versus composition expressed in apfu, indicating a close link between atomic-scale and bulk properties. Weight fraction and density are relative proportions (dependent on formula weight), producing curves in all plots involving weight fraction of ions or $D$ (Bloss 1952).

In general, there is a net increase in index of refraction if the substituting elements have increased ionic charge, increased atomic number, or decreased atomic radius (e.g., $\mathrm{Fe}^{2+}$ for $\mathrm{Mg}$, $\mathrm{Ca}$ for $\mathrm{Na}, \mathrm{Na}$ for $\mathrm{K}, \mathrm{Ba}$ for $\mathrm{K}$, $\mathrm{Fe}^{3+}$ for $\mathrm{Al}, \mathrm{Fe}^{3+}$ for $\mathrm{Fe}^{2+}, \mathrm{OH}$ for $\left.\mathrm{F}\right)$. The majority of cation-exchange mechanisms produce increased index of refraction and increased density with increased atomic number, but some anion-exchange mechanisms reveal a decreased index of refraction with increased density $\left[e . g,(\mathrm{OH})_{-1} \mathrm{~F}\right.$ in topaz]. The cations may be modeled by a formal charge radiating from the spherical surface of the core of a noble gas configuration (Fig. 1). By contrast, the outer valence-electrons of anions may not have spherical (ionic) orbitals, but can be located between ions to give the bond a covalent character (Zoltai \& Stout 1984). There is an overall increased index of refraction and decrease in density for compounds with increasingly covalent bonds (Jaffe 1988). This pattern confirms the idea that the refracted path of a photon is sensitive to the density and distribution of electrical charge about each ion and through the structure. The photon is then a probe of this atomic arrangement and crystal structure. Physically, the changed physical properties are all due to the opposing effects of atomic number and ionic radius, encapsulated by the radial electrical field-gradient $($ Volt $/ \mathrm{m})$ as modified by the local environment of bonding in the crystal structure. In addition to identifying the refracting ion and its valence state, optical analysis shows that ionic refraction decreases with increasing coordination-number (Eggleton 1991); thus the site occupancy can be determined. In consequence, the mineral's structural formula can be constrained by measurement of its physical properties $(n, a, D)$.

\section{Optical Analysis}

Optical analysis, the method of calculating the net index of refraction from the ionic values of specific refractivity, is a distinct method of compositional analysis. But in optical analysis, the net refraction of each sample across a compositional series is explained as a sum of contributions of individual ions, each varying directly with weight fraction (rather like the structure factor of X-ray crystallography). The values of $k$ are solved by analyzing the data for index of refraction and density of minerals of well-characterized composition and structural state; specific values of $n$ and $D$ characterize each state.
Minerals need not be established as optical reference states, as light is the primary standard for distance, time and energy. Measurement of the wavelength of light has replaced a physical standard for the meter. Characterization of the resonant frequency of an atomic transition is the basis of the atomic clock. The proposed constant velocity of light relates the distance and time measurements, according to $c=\mathrm{d} / t$. Accurate determination of the Planck constant $h$ gives a standard for energy, i.e., $E=h f$. For minerals, a specific composition and structural state must give the expected index of refraction and unit-cell parameter from well-characterized sources of light.

Indices of refraction can be measured to four or more significant figures (within $0.5 \%$, depending on the method), and there is room for increased accuracy. Very pure halite at $293 \mathrm{~K}$ and $1 \mathrm{~atm}$ has $a$ equal to $0.564009(3) \mathrm{nm}$ and $n=1.54416(4)$, determined for sodium light of $\lambda$ equal to 589.301(1) nm (Nikogosyan 1997). Refined unit-cell parameters can be accurate to five or more significant figures (within $0.1 \%$, Herbstein 2000). The limiting factor for optical analysis seems to be measurement of composition, with electron-microprobe results presently limited to about $1 \%$ precision and 2-4\% accuracy (e.g., Teertstra et al. 1998).

Experimentally, each index $n$ is measured at a specific energy of light (e.g., the $2.15 \mathrm{eV}$ or $589.3 \mathrm{~nm}$ yellow spectral line from a sodium lamp, or light-emitting diode, laser or laser diode). Care must be taken to interpret the atypical indices of refraction that occur for any energy of light near an energy of atomic absorption. The liquid-immersion technique is the most common. If the index of the grain matches the index of the immersion liquid, monochromatic light passes through both without deflection and the grain is invisible. Alternatively, index of refraction can be determined by beam deflection, that is, by measuring the change of angle as light refracts into and then out of a grain held in air. A time delay could also be measured, relative to light traveling the same distance in a vacuum, with $n=t_{\text {mineral }} / t_{\text {vacuum }}$.

Optical analysis starts by noting that index of refraction changes in direct proportion to the bulk density, $n \propto D$. Call the constant of proportionality $K$; as a result, $n=K D$, and $n / D=K$. In a plot of $n$ versus $D$, each material is characterized by its net refraction per unit density. Any two materials are then related by a slope $\Delta n / \Delta D$. A continuous mechanism of substitution, such as the $\mathrm{Mg}_{-1} \mathrm{Fe}$ exchange vector from pyrope $\mathrm{Mg}_{3} \mathrm{Al}_{2}$ $\mathrm{Si}_{3} \mathrm{O}_{12}$ to almandine $\mathrm{Fe}_{3} \mathrm{Al}_{2} \mathrm{Si}_{3} \mathrm{O}_{12}$, defines a line through $n-D-$ composition space. The exchange vector defines the direction, but the magnitude is $\Delta n / \Delta D$ per mole.

Values for the specific refraction of light by each element are solved by guess-and-iteration with respect to a controlled change of composition. A number of relations involving $n, D$ and composition have been proposed. All of these methods derive specific refractive values $k$ of molar refractivity (constants to be multiplied 
by the weight fraction or concentration of the oxide or element), but differ in their manipulation of the refractive data. Below, I focus on the Gladstone-Dale equation, $(n-1) / D=\Sigma\left[\left(k_{\text {oxide }}\right)(\right.$ weight oxide $\left.)\right]$, but find a simpler equation that is more useful to the structural formulae of minerals: $n / D=\Sigma\left[\left(k_{\text {ion }}\right)\right.$ (weight ion) $]$.

\section{The Gladstone-Dale Relation}

The original relation of Gladstone \& Dale (1864) is $(n-1) / D=K=\Sigma\left(k_{0} w_{0}\right)$, where density $D=m / V(\mathrm{~g} /$ $\mathrm{cm}^{3}$ ), and $k_{\mathrm{o}}$ is the variable "specific refractive energy" (their term) of each oxide (o) of weight fraction $w_{0}$ (in grams per $100 \mathrm{~g}$ ). With a set of average $k_{\mathrm{o}}$ values, the relation $(n-1) / D=\Sigma\left(k_{\mathrm{o}} w_{\mathrm{o}}\right)$ allows comparison of calculated and measured indices of refraction, and has been used in this way. The compatibility index of Mandarino (1976) gives an excellent check on the accuracy of results of a chemical analysis. The Gladstone-Dale relation is particularly useful in predicting the properties of new glass or crystal compositions.

The iterative best-fit method of solution requires $k_{\mathrm{o}}$ values as "Gladstone-Dale constants" (Mandarino 1976 ), but $k_{\mathrm{o}}$ actually varies with the atomic environment and varies between mineral groups (Eggleton 1991). So the original term "specific refractive energy" remains evocative of the physical process, with atomic electrical potential available for the refraction of light, except that the $k_{\mathrm{i}}$ are not a form of energy.

Gladstone \& Dale (1864) analyzed minerals using $(n-1)$, the optical displacement. Light traveling through $1 \mathrm{~m}$ of water $\left(n=1.33=d_{\text {water }} / d_{\text {vacuum }}\right)$ has a displacement of $0.33 \mathrm{~m}$, equal to the optical path length minus the sample thickness (the geometrical path-length). The distance $(n-1)$ is the net displacement perpendicular to the direction of propagation and in the electrical plane of plane-polarized light. The electrical force causing refraction acts only along the electrical vector of light, not along the direction of propagation, so the light does not change energy, wavelength or color.

The left side of the equation, $(n-1) / D$, relies on macroscopic physical measurements on bulk material. For each fixed composition, the index of refraction is converted to a displacement (as in the example with water) and normalized to the density. This approach gives equivalence of weight fraction and density fraction. The term $(n-1) / D$ forms a crude but effective normalizing structure-factor that automatically accounts for variation of temperature and pressure. Increased temperature results in decreased density by increasing the distance between refracting elements; this increase also decreases the refraction. The present analysis is restricted to $n, D$ states defined at $298 \mathrm{~K}$ and $1 \mathrm{~atm}$. Relations to variable composition are found from $(n-1) \mathrm{V} /$ $\Sigma m$, wherein a number of elements contribute atomic mass to volume $V$. Note that by measuring $\Delta$ mass and $\Delta \mathrm{V}$ with varied composition, it is possible to iteratively solve for atomic weights! Atomic weight is considered here as a constant, even though inertial mass changes slightly with bond formation at constant electron and proton charge.

The right side of the equation, $\Sigma\left(k_{0} w_{\mathrm{o}}\right)$, requires atom parameters to explain the net index of refraction and bulk density. Breaking up the net index of refraction into corresponding weight-fractions gives an immediate crude estimate of the refraction due to each element. With varied composition, guess-and-iteration allows convergence to a "specific refractivity" $k_{\mathrm{o}}$ for each oxide of weight fraction $w_{\mathrm{o}}$. The procedure is similar to that used to empirically determine ionic radii. This works if typical values are found for $k_{\mathrm{o}}$ that ascribe a specific power of refraction to each element in a similar environment of bonding, and this is generally the case.

Refraction is sensitive to crystal structure as well as to composition. Application of the Gladstone-Dale relation to structural polymorphs (e.g., of $\mathrm{SiO}_{2}$ or $\mathrm{Al}_{2} \mathrm{SiO}_{5}$ ) gives a range of $k_{\mathrm{o}}$ values with respect to structure type and coordination number. This range indicates two matters of interest, the grand mean values of $k_{\mathrm{o}}$ broadly applicable to all minerals, and the specific values of $k_{\mathrm{o}}$ characteristic of element substitution in a particular structure-type.

To extend the Gladstone-Dale relation to anisotropic crystals (Larsen 1921), a mean or average $n$ has been be used. Closer relations between calculated and observed indices are found by using the ellipsoidal refractive (indicatrix) volumes $4 \pi n^{3} / 3,4 \pi\left(\omega^{2} \varepsilon\right) / 3$ and $4 \pi(\alpha \beta \gamma) / 3$ (Allen 1956), or mean indices $\left(\omega^{2} \varepsilon\right)^{1 / 3}$ and $(\alpha \beta \gamma)^{1 / 3}$ in place of averages $(2 \omega+\varepsilon) / 3$ and $(\alpha+\beta+$ $\gamma) / 3$, respectively. But one might not want to average the refraction data for birefringent crystals if structural information can be extracted! For one composition, a crystal may have up to three principal orthogonal indices of refraction, indicating directional variations in the structure. The relations with composition can be obtained using individual values of $\varepsilon$ or $\omega$, and $\alpha, \beta$ or $\gamma$, and this is important for biaxial minerals with ready access to indices only on a basal cleavage (e.g., the micas). It is simplest and correct to use individual values of refraction specific to the direction of an experimental path of photons through the crystal.

The values of $k_{\mathrm{o}}$ are derived by guess-and-iteration using $n, D$ data from minerals and compositional series (Larsen 1921, Allen 1956, Jaffe 1956, 1988, Mandarino 1976, and references therein, Bloss et al. 1983, Eggleton 1991). The values of $k_{\mathrm{o}}$ determined for pure oxides such as $\mathrm{SiO}_{2}$ or $\mathrm{Al}_{2} \mathrm{O}_{3}$, with $w_{\mathrm{o}}=1$ and $k_{\mathrm{o}}=K=(n-1) / D$, have been used as reference points to examine more complex materials. For mineral groups, the average values of $k_{\mathrm{o}}$ can also be estimated by the least-squares best fit between observed and calculated values of $(n-1) / D$ for many samples (Bloss et al. 1983). If one uses leastsquare methods to derive average values of $k$ for complex solid-solution series, convergence to false minima is quoted as possible, and the results may be influenced by both the path and method of iteration (Eggleton 
1991). The values of $k$ depend on the choice of accurate $n-D$ - composition data, so the sources of data must be stated.

The values of $k$ for other minerals may be used, commonly $k\left(\mathrm{SiO}_{2}\right)$ from quartz, to questionable accuracy: $k\left(\mathrm{Si}^{4+}\right), k\left(\mathrm{O}^{2-}\right)$ and the combined $k\left(\mathrm{SiO}_{2}\right)$ vary with the structure of the polymorphs. I found that an unknown $k(\mathrm{MgO})$ of $\mathrm{Mg}_{3} \mathrm{Al}_{2} \mathrm{Si}_{3} \mathrm{O}_{12}$ garnet is determined by dividing the difference $K-k\left(\mathrm{SiO}_{2}\right) w\left(\mathrm{SiO}_{2}\right)-k\left(\mathrm{Al}_{2} \mathrm{O}_{3}\right)$ $w\left(\mathrm{Al}_{2} \mathrm{O}_{3}\right)$ by the weight fraction $w(\mathrm{MgO})$, a calculation that leaves the observed data $(n-1) / D$ invariant. The derived value of $k(\mathrm{MgO})=\left[K-k\left(\mathrm{SiO}_{2}\right) w\left(\mathrm{SiO}_{2}\right)-\right.$ $\left.k\left(\mathrm{Al}_{2} \mathrm{O}_{3}\right) w\left(\mathrm{Al}_{2} \mathrm{O}_{3}\right)\right] / w(\mathrm{MgO})$ depends on the value $k\left(\mathrm{Al}_{2} \mathrm{O}_{3}\right)$; however, both vary with the choice of $k\left(\mathrm{SiO}_{2}\right)$, and this changes from quartz to garnet.

As it stands, the Gladstone-Dale relation is not in its most useful form. If minerals are analyzed by chemical dissolution and precipitation of oxides, it is convenient to report the results as weight percent oxides. Expression as an oxide implies known valence, but valence is readily expressed within the structural formula. If the calculation of a mineral formula involves conversion between oxides and elemental weights $\left(e . g\right.$., $\mathrm{Fe}_{2} \mathrm{O}_{3}$ to $\mathrm{Fe})$, it is necessary to interconvert $k$-oxide and $k$-ion values. The oxide values combine the atomic weights and values of refractivity $k$ for each ion component. Using oxides to represent mineral formulae is archaic and inconvenient. Ionic $k_{\mathrm{i}}$ values, using weight fractions of elements and numbers of atoms per formula unit, are preferred to identify the specific contribution of oxygen to refractivity and to give direct relations to mineral formulae.

\section{EXPANSION OF TERMS}

Values of refractivity $k$ can be determined for virtually any manipulation of the data for index of refraction: $n,(n-1),(n-2), n^{2}, n^{3},\left(n^{2}-1\right) /\left(n^{2}+2\right)$ and so on, but relations to the physical process of refraction remain to be demonstrated. Dimensional analysis of the Gladstone-Dale relation gives units of $\mathrm{cm}^{3} / \mathrm{g}$ to $k$, as the density or weight fraction is unitless. Calculating the refracting volume of an ion according to $\mathrm{V}_{\mathrm{r}}=\left(k_{\mathrm{i}}\right) \mathrm{AW} /$ $A_{N}$, where $A_{N}$ is Avogadro's number, gives the appropriate atomic scale for known ionic radii, but only for values of $k$ derived from the simplest relation, $K=n / D$ $=\Sigma\left(k_{\mathrm{i}} w_{\mathrm{i}}\right)$. Regardless, the following analysis is applicable to any form of manipulation of the data on index of refraction.

I could not find a means to transpose values of $k$ derived from the $(n-1) / D$ form to those derived from the $n / D$ form. I wanted to use $k$ data for oxides from the literature to extract $k$ values for ions, but the $n, D$ data of the reference samples are unstated, and the $k$ values for oxides are skewed by use of a mean $k\left(\mathrm{SiO}_{2}\right)$ of quartz, which is inappropriate in an unrelated structure.

With the index of refraction normalized to the bulk density by $K=n / D$, values of refractivity $k$ can be de- termined with respect to each analytically established weight-fraction $(w)$ according to $K=\Sigma\left(k_{\mathrm{o}} w_{\mathrm{o}}\right)$ for oxides, or $K=\Sigma\left(k_{\mathrm{i}} w_{\mathrm{i}}\right)$ for ions, respectively. Each component has a relative fractional contribution to $n / D$; this is $k w$, but the absolute contribution $\left|n_{\mathrm{i}}\right|$ is $D k w$. The advantage of using $(n / D)$-normalized values is that the unitless weight-fraction $w$ is also the fractional contribution to density, with $w_{\mathrm{i}}=d_{\mathrm{i}}$ and $\Sigma w_{\mathrm{i}}=1$. For a pure compound such as $\mathrm{SiO}_{2}, w_{\mathrm{o}}=1$ and $k_{\mathrm{o}}=n / D$. The absolute contribution of each ion to the density is $\left|d_{\mathrm{i}}\right|=m_{\mathrm{i}} / V$ $=w_{\mathrm{i}} D$. The absolute contribution of each ion to the index of refraction is $\left|n_{\mathrm{i}}\right|=k_{\mathrm{i}}\left|d_{\mathrm{i}}\right|$.

The exact solution of $k_{\mathrm{i}}$ values is preferred over average or best-fit approximations. Any solution of $k_{\mathrm{i}}$ values should leave the observed data $n / D$ invariant, returning exactly the definition of state. The constraint of zero net change of $\Sigma\left(k_{\mathrm{i}} w_{\mathrm{i}}\right)$ values is unusual for linear algebra, but occurs because the $n_{\mathrm{i}}$ contribution of each element to the index of refraction $n$ is iterated along fixed lines of $d_{\mathrm{i}}$ (or the contribution of absolute density in a plot of $\left|n_{\mathrm{i}}\right|$ versus $\left.\left|d_{\mathrm{i}}\right|\right)$. The iterative process alters the slope $n_{\mathrm{i}} / d_{\mathrm{i}}$. This is more evident in vector space, where each $k_{\mathrm{i}} w_{\mathrm{i}}$ is a vector of direction $k_{\mathrm{i}}$ and magnitude $w_{\mathrm{i}}$ contributing to the resultant $n / D$. Vector addition is normally done by projection of components onto the $\mathrm{x}$ and $\mathrm{y}$ axis, in this case $\Sigma n_{\mathrm{i}}$ and $\Sigma d_{\mathrm{i}}$. Each vector $k_{\mathrm{i}} w_{\mathrm{i}}$ is tied head to tail to the next, but constrained along $w_{\mathrm{i}}=d_{\mathrm{i}}$ to give $K=\Sigma k_{\mathrm{i}} w_{\mathrm{i}}$. By refining $k_{\mathrm{i}}$ in $\mathrm{cm}^{3} / \mathrm{g}$, each value $n_{\mathrm{i}}$ is automatically refined with an anchor at $\left|d_{\mathrm{i}}\right|=$ $\left(a_{\mathrm{i}} \mathrm{AW}_{\mathrm{i}}\right) / \mathrm{FW}=m_{\mathrm{i}} / V_{\text {cell }}$ in $\mathrm{g} / \mathrm{cm}^{3}$.

In contrast to glass, the translational symmetry of minerals allows identification of a distinct unit-cell. Operations of symmetry also describe constraints on the structural formula. If results of a complete analysis are available, and if unit-cell dimensions are refined from $\mathrm{X}$-ray-diffraction data, then the $D$ term expands to $D=$ $\Sigma\left(a_{\mathrm{i}} m_{\mathrm{i}}\right) / V=\Sigma\left(a_{\mathrm{i}} \mathrm{AW}\right) / V \mathrm{~A}_{\mathrm{N}}$, where a number of atoms $a_{\mathrm{i}}$ of atomic weight AW contribute mass $m_{\mathrm{i}}$ to the unitcell volume $V$.

To determine $n_{\mathrm{i}}$, simply multiply $\left(k_{\mathrm{i}}\right) \mathrm{AW}$ by the number of atoms contributing to the formula weight $\left(a_{\mathrm{i}}\right)$ $\mathrm{FW}$ ), as read directly from the mineral formula. Consider almandine, $\mathrm{Fe}^{2+}{ }_{3} \mathrm{Al}_{2} \mathrm{Si}_{3} \mathrm{O}_{12}$, in which $\mathrm{Fe}^{2+}$ contributes $k\left(\mathrm{Fe}^{2+}\right)(3 \mathrm{AW} F \mathrm{Fe}) / \mathrm{FW}$ to the total $\Sigma\left(k_{\mathrm{i}} w_{\mathrm{i}}\right)$. The formula of the garnet $\left(\mathrm{Fe}_{2} \mathrm{Mg}\right) \mathrm{Al}_{2} \mathrm{Si}_{3} \mathrm{O}_{12}$ is now indicated in $K=\left[k\left(\mathrm{Fe}^{2+}\right)\left(2 \mathrm{AW}_{\mathrm{Fe}}\right)+k\left(\mathrm{Mg}^{2+}\right)\left(\mathrm{AW}_{\mathrm{Mg}}\right)+\right.$ $\left.k\left(\mathrm{Al}^{3+}\right)\left(2 \mathrm{AW}_{\mathrm{Al}}\right)+k\left(\mathrm{Si}^{4+}\right)\left(3 \mathrm{AW}_{\mathrm{Si}}\right)+k\left(\mathrm{O}^{2-}\right)\left(12 \mathrm{AW}_{\mathrm{O}}\right)\right] /$ $\mathrm{FW}$. This expression gives a direct relation between $n$ or $D$ and changing $\mathrm{Fe} /(\mathrm{Fe}+\mathrm{Mg}), \mathrm{Fe}$ or $\mathrm{Mg} a p f u$, or the molar percentage of end-member almandine or pyrope. The value $k\left(\mathrm{Al}_{2} \mathrm{Si}_{3} \mathrm{O}_{12}\right)$ varies by change in the relative proportion of $w\left(\mathrm{Al}_{2} \mathrm{Si}_{3} \mathrm{O}_{12}\right)$, due to change in MW/FW that produces a curve across the compositional series, and by structural changes induced by substitution at the $X$ site. This interesting new form of the Gladstone-Dale relation allows exploration of variation in refractivity with respect to crystallographic constraints, such as 3 apfu occupancy of tetrahedral sites by $\mathrm{Si}$, by providing 
a means to isolate the contributions to refraction and density of any chosen structural unit. Therefore, we need not insert the $k\left(\mathrm{SiO}_{2}\right)$ of quartz to accurately resolve the $k_{\mathrm{i}}$ value of a cation.

The oxide $k$-values transpose into ion $k$-values as follows. For a given value of $k\left(\mathrm{O}^{2-}\right)$, the transformation $k\left(\mathrm{Fe}^{2+}\right) w(\mathrm{Fe})=k(\mathrm{FeO}) w(\mathrm{FeO})-k\left(\mathrm{O}^{2-}\right) w(\mathrm{O})$ leaves $n / D$ invariant. The $w(\mathrm{O})$ here is only that weight fraction of oxygen associated with $\mathrm{FeO}, w(\mathrm{O})=w_{\mathrm{o}}\left(a_{\mathrm{i}} \mathrm{AW}_{\mathrm{O}}\right) /$ $\left(\mathrm{MW}_{\mathrm{FeO}}\right)$, where $w_{\mathrm{O}}$ is the weight fraction of oxide, and $a_{\mathrm{i}}$ is the number of atoms of oxygen per unit of $\mathrm{FeO}$, simply $w(\mathrm{O})=w(\mathrm{FeO})-w(\mathrm{Fe})$. For magnesian almandine, $\left(\mathrm{Fe}_{2} \mathrm{Mg}\right) \mathrm{Al}_{2} \mathrm{Si}_{3} \mathrm{O}_{12}$, using $k(\mathrm{FeO})=0.188, k(\mathrm{MgO})$ $=0.200, k\left(\mathrm{Al}_{2} \mathrm{O}_{3}\right)=0.207, k\left(\mathrm{SiO}_{2}\right)=0.208$ and $k\left(\mathrm{O}^{2-}\right)$ $=0.203$ (average values for minerals from Mandarino $1976)$, the ionic $k$-values are $k\left(\mathrm{Fe}^{2+}\right)=0.184, k\left(\mathrm{Mg}^{2+}\right)=$ $0.198, k\left(\mathrm{Al}^{3+}\right)=0.211$ and $k\left(\mathrm{Si}^{4+}\right)=0.214$.

\section{REFINING $k_{\text {ION }}$ VALUES OF REFRACTIVITY}

Values of $k_{\text {ion }}$ can be refined for any change in index of refraction or density $\Delta n / \Delta \mathrm{D}$ due to a specific substitution (e.g., $\mathrm{Fe}^{2+}$ for $\mathrm{Mg}$ ). The iteration is accomplished most quickly with a spreadsheet; I used Sigma Plot. The $n, a, D$ data for pure synthetic end-member garnet-group minerals are given in Table 1 (Skinner 1956). The $n, a$ data for intermediate compositions were found by linear interpolation, and $D$ was calculated.

Begin with a balanced equation, the solution in which each $k_{\mathrm{i}}=K$. Trying a new $k_{\mathrm{i}}=K+x, n / D$ remains invariant if the sum $\left(k_{\mathrm{i}} w_{\mathrm{i}}\right)$ is constant. Across the series $(\mathrm{Fe}, \mathrm{Mg})_{3} \mathrm{Al}_{2} \mathrm{Si}_{3} \mathrm{O}_{12}$, the values $k\left(\mathrm{Fe}^{2+}\right)$ and $k\left(\mathrm{Mg}^{2+}\right)$ can be resolved by change of $a_{\mathrm{Fe}}$ and $a_{\mathrm{Mg}}$ along $\mathrm{Mg}_{-1} \mathrm{Fe}$ at constant $\mathrm{Al}_{2} \mathrm{Si}_{3} \mathrm{O}_{12}$ in the formula unit. Grouping the $\mathrm{Al}_{2} \mathrm{Si}_{3} \mathrm{O}_{12}$ components leaves the equations with two independent variables, $k\left(\mathrm{Fe}^{2+}\right)$ and $k\left(\mathrm{Mg}^{2+}\right)$. At fixed $k\left(\mathrm{Fe}^{2+}\right) w(\mathrm{Fe})$, increasing $k\left(\mathrm{Mg}^{2+}\right)$ increases $k\left(\mathrm{Mg}^{2+}\right)$ $w(\mathrm{Mg})$, whereas $K\left(\mathrm{Al}_{2} \mathrm{Si}_{3} \mathrm{O}_{12}\right) w\left(\mathrm{Al}_{2} \mathrm{Si}_{3} \mathrm{O}_{12}\right)$ decreases by $K\left(\mathrm{Mg}^{2+}\right) w(\mathrm{Mg})-k\left(\mathrm{Mg}^{2+}\right) w(\mathrm{Mg})$. Dividing $\left[K\left(\mathrm{Al}_{2} \mathrm{Si}_{3}\right.\right.$ $\left.\left.\mathrm{O}_{12}\right) w\left(\mathrm{Al}_{2} \mathrm{Si}_{3} \mathrm{O}_{12}\right)-k\left(\mathrm{Mg}^{2+}\right) w(\mathrm{Mg})\right]$ by the fixed $w\left(\mathrm{Al}_{2} \mathrm{Si}_{3} \mathrm{O}_{12}\right)$ gives the new $k\left(\mathrm{Al}_{2} \mathrm{Si}_{3} \mathrm{O}_{12}\right)$. A linear relation is found in a plot of $k\left(\mathrm{Al}_{2} \mathrm{Si}_{3} \mathrm{O}_{12}\right)$ versus $k\left(\mathrm{Mg}^{2+}\right)$. The slope $\mathrm{m}_{1}$ of the linear equation $k\left(\mathrm{Al}_{2} \mathrm{Si}_{3} \mathrm{O}_{12}\right)=$ $\mathrm{m}_{1} k\left(\mathrm{Mg}^{2+}\right)+\mathrm{b}_{1}$ is solved using two values of $k\left(\mathrm{Mg}^{2+}\right)$,

TABLE 1. REFERENCE STATES OF GARNET END-MEMBERS

\begin{tabular}{llccc}
\hline Species & formula & $n$ & $\begin{array}{c}a \\
\mathrm{~nm}\end{array}$ & $\begin{array}{c}D_{\mathrm{cad}} \\
\mathrm{g} / \mathrm{cm}^{3}\end{array}$ \\
\hline Pyrope & $\mathrm{Mg}_{3} \mathrm{Al}_{2} \mathrm{Si}_{3} \mathrm{O}_{12}$ & 1.714 & 1.1459 & 3.5591 \\
Grossular & $\mathrm{Ca}_{3} \mathrm{Al}_{2} \mathrm{Si}_{3} \mathrm{O}_{12}$ & 1.734 & 1.1851 & 3.5898 \\
Spessartine & $\mathrm{Mn}_{3} \mathrm{Al}_{2} \mathrm{Si}_{3} \mathrm{O}_{12}$ & 1.800 & 1.1621 & 4.1902 \\
Almandine & $\mathrm{Fe}_{3} \mathrm{Al}_{2} \mathrm{Si}_{3} \mathrm{O}_{12}$ & 1.830 & 1.1526 & 4.3184 \\
\hline
\end{tabular}

Values taken from. Skinner (1956) whereas the intercept $b_{1}$ remains variable, dependent on the choice of $k\left(\mathrm{Fe}^{2+}\right)$ (Fig. 2).

Next, with a fixed $k\left(\mathrm{Mg}^{2+}\right)$, the line $k\left(\mathrm{Al}_{2} \mathrm{Si}_{3} \mathrm{O}_{12}\right)=$ $\mathrm{m}_{2} k\left(\mathrm{Fe}^{2+}\right)+\mathrm{b}_{2}$ is defined. The two lines intersect at a single value of $k\left(\mathrm{Al}_{2} \mathrm{Si}_{3} \mathrm{O}_{12}\right)$, with $\mathrm{m}_{1} k\left(\mathrm{Mg}^{2+}\right)+\mathrm{b}_{1}=$ $\mathrm{m}_{2} k\left(\mathrm{Fe}^{2+}\right)+\mathrm{b}_{2}$, indicating that false convergence will not occur (Fig. 2). This intersection gives a precise set of $k$-values to explain $n$ and $D$ in the series pyrope-almandine, even if the three $k$-values are not unique [in this example, they are dependent on the choice of the $k\left(\mathrm{Fe}^{2+}\right)$ value]. At this stage, there is no practical advantage over $n-D$-composition determinative curves, but the ion weight-fractions now directly relate to numbers of atoms per formula unit in an equation for variation of $n$ and $D$ specific to the $\mathrm{Mg}_{-1} \mathrm{Fe}$ vector.

A well-characterized ternary solid-solution defines accurate $k$-values, as single values of $k\left(\mathrm{Fe}^{2+}\right)$ and $k\left(\mathrm{Al}_{2} \mathrm{Si}_{3} \mathrm{O}_{12}\right)$ must satisfy the $n / D$ of all samples along both $\mathrm{Mn}_{-1} \mathrm{Fe}$ and $\mathrm{Mg}_{-1} \mathrm{Fe}$ (Fig. 3). This $k\left(\mathrm{Fe}^{2+}\right)$ is now used to solve the equations $k\left(\mathrm{Al}_{2} \mathrm{Si}_{3} \mathrm{O}_{12}\right)=\mathrm{m}_{1} k\left(\mathrm{Mg}^{2+}\right)+$ $\mathrm{b}_{1}$ and $k\left(\mathrm{Al}_{2} \mathrm{Si}_{3} \mathrm{O}_{12}\right)=\mathrm{m}_{2} k\left(\mathrm{Fe}^{2+}\right)+\mathrm{b}_{2}$. With one common element, two exchange vectors give $k$ values for four variables in five equations, in this case $k\left(\mathrm{Fe}^{2+}\right)$, $k\left(\mathrm{Mg}^{2+}\right), k\left(\mathrm{Mn}^{2+}\right)$ and $k\left(\mathrm{Al}_{2} \mathrm{Si}_{3} \mathrm{O}_{12}\right)$. So the set of $k$ values is defined for complex (rather than simple) solidsolutions if the site occupancies are known. One must try various $k$-values of the common element that allows convergence to single $k$-values of the remaining elements. Note that the substitutions need not be at the same crystallographic site, but may be coupled to another site (for example, ${ }^{X} \mathrm{Ca}^{2+}+{ }^{Z} \mathrm{Si}^{4+}={ }^{X} \mathrm{Y}^{3+}+{ }^{\mathrm{Z}} \mathrm{Al}^{3+}$ ).

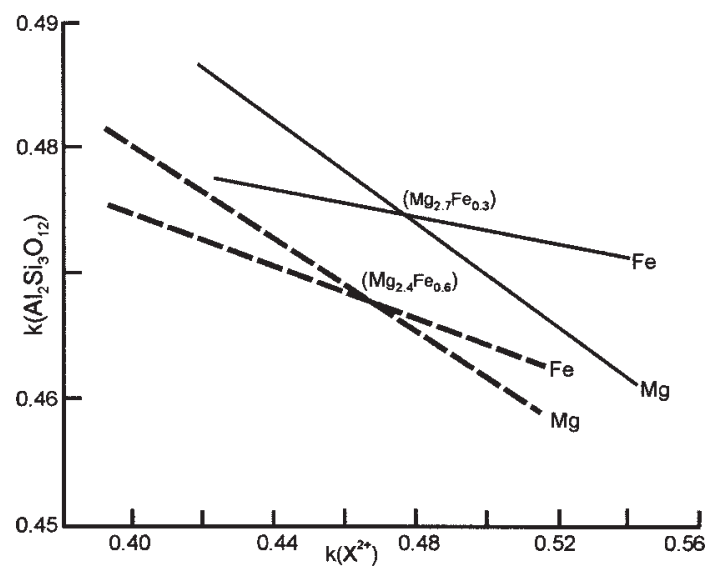

FIG. 2. Variation in the value of refractivity $k\left(\mathrm{Al}_{2} \mathrm{Si}_{3} \mathrm{O}_{12}\right)$ with choice of $k\left(X^{2+}\right)$. For each composition (solid lines: $\mathrm{Mg}_{2.7} \mathrm{Fe}_{0.3} \mathrm{Al}_{2} \mathrm{Si}_{3} \mathrm{O}_{12}$; dashed lines; $\mathrm{Mg}_{2.4} \mathrm{Fe}_{0.6} \mathrm{Al}_{2} \mathrm{Si}_{3} \mathrm{O}_{12}$ ), lines of $k\left(\mathrm{Fe}^{2+}\right)$ and $k\left(\mathrm{Mg}^{2+}\right)$ versus $k\left(\mathrm{Al}_{2} \mathrm{Si}_{3} \mathrm{O}_{12}\right)$ intersect at a single value of $k\left(\mathrm{Al}_{2} \mathrm{Si}_{3} \mathrm{O}_{12}\right)$. However, the system cannot be solved to give absolute values because the line intercepts vary with the initial choice of $k\left(X^{2+}\right)$. 
With the assumption of constant $k$-values to explain the $n, D$ data of all $X_{3} \mathrm{Al}_{2} \mathrm{Si}_{3} \mathrm{O}_{12}$ garnets, the accuracy of the convergence is limited. Slightly different values of $k\left(\mathrm{Fe}^{2+}\right), k\left(\mathrm{Mg}^{2+}\right), k\left(\mathrm{Mn}^{2+}\right), k\left(\mathrm{Ca}^{2+}\right)$ and $k\left(\mathrm{Al}_{2} \mathrm{Si}_{3} \mathrm{O}_{12}\right)$ best suit each end-member. At this stage, I found the assumption of constant $k$-values good but insufficient to exactly reproduce the observed covariation of $n$ and $D$ across wide ranges of composition (within error of measurement; Table 1) across wide ranges of composition. The best convergence of $k$ values (Table 2 ) is found for comparative samples that differ from the central composition only by an amount sufficient to produce a measurable difference in $n$ or $D$. For example, excellent convergence was attained between end-member pyrope and samples with $\mathrm{Mg}_{2.7} X_{0.3} \mathrm{Al}_{2} \mathrm{Si}_{3} \mathrm{O}_{12}$ and $\mathrm{Mg}_{2.4} X_{0.6} \mathrm{Al}_{2}$ $\mathrm{Si}_{3} \mathrm{O}_{12}$, with $X=\mathrm{Fe}, \mathrm{Mn}, \mathrm{Ca}$. This convergence represents agreement of refined $k$-values with the same accuracy as the input data for index of refraction and unit-cell dimension, potentially exceeding the accuracy of analysis with an electron microprobe.

It is not possible to claim that an inaccurate low measurement of refraction in a Fe-rich sample contributes to a low calculated value of refraction in an $\mathrm{Fe}$ bearing Mg-rich sample. This set of $k$ values for ( $\mathrm{Fe}, \mathrm{Mg}, \mathrm{Mn}, \mathrm{Ca}) \mathrm{Al}_{2} \mathrm{Si}_{3} \mathrm{O}_{12}$ garnets was derived to leave the observed data invariant. Linear algebraic equations must exactly return the $n, D$ values, but this is done by linear variation of $k$ values.

Physically, constant $k$-values are not expected. A cation coordinates to an oxygen ion by favorable binding of electrostatic forces, and this changes the radial

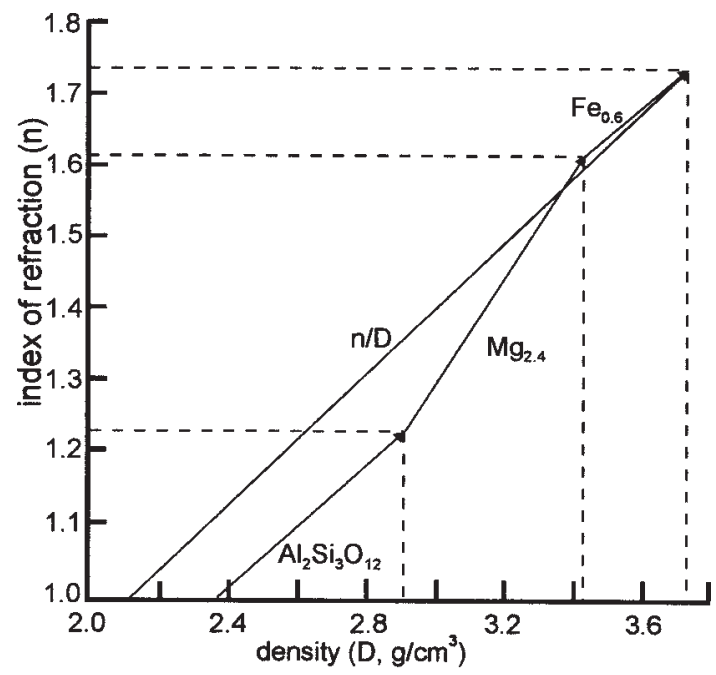

FIG. 3. Index of refraction $n$ versus density $D$. The grand mean vector $(n / D)$ is the resultant of the vector contributions of $0.6 \mathrm{Fe}, 2.4 \mathrm{Mg}$ and $1 \mathrm{Al}_{2} \mathrm{Si}_{3} \mathrm{O}_{12}$ per formula unit to $n$ and $D$. position of the energy level at which a photon refracts. The $k_{\mathrm{i}}$ of a cation decreases with increasing $\langle X-\mathrm{O}\rangle$ interatomic distance. $\mathrm{The}_{\mathrm{Mg}^{2+}}$ ion in Mn-rich garnet occupies a larger $X$-site than in pyrope (Novak \& Gibbs 1971); it has a slightly decreased power to refract light. The $k_{\mathrm{i}}$ of a cation decreases with decreasing cationcation distances.

The $k_{\mathrm{i}}$ values are not a direct indication of the refractive power of an ion, but this is given by the ion's refracting volume $V_{\mathrm{r}}=\left(k_{\mathrm{i}}\right) \mathrm{AW} / \mathrm{A}_{\mathrm{N}}$, where $\mathrm{AW}$ is the atomic weight of an ion, and $A_{N}$ is Avogadro's number. The refracting volumes are of appropriate atomic scale for refraction of $2.15 \mathrm{eV}$ yellow light (Table 3) and indicate a quantity of charge at a specific radius from the nucleus. The larger cations place $2+$ units of charge further out from the nucleus, so the refracting volumes increase with ionic radius according to $\mathrm{Mg}<\mathrm{Fe}<\mathrm{Mn}<$ Ca (Novak \& Gibbs 1971).

The linear correction-factors for almandinespessartine are $k^{\prime}\left(\mathrm{Fe}^{2+}\right)=k\left(\mathrm{Fe}^{2+}\right)$ Alm $+\mathrm{xMn}$, and $k^{\prime}\left(\mathrm{Mn}^{2+}\right)=k\left(\mathrm{Mn}^{2+}\right)_{\mathrm{Sps}}+\mathrm{yMn}($ apfu $)$. What arises for the garnet group as a whole is a matrix correction for varying $k$-values. The values in this matrix describe the refraction of $2.15 \mathrm{eV}$ yellow-light photons about each site through each species of garnet. This matrix must return the exact values of $n, D$ and composition of the standards within the quoted limits of precision and accuracy (Table 2).

Once $k_{\mathrm{i}}$ values are established for a specific structure-type, the $w_{\mathrm{i}}$ of an unknown mineral is varied along each fixed $k_{\mathrm{i}}$ to give an optical estimate of composition. Within the constraints of a known structural formula, an initial composition is proposed and then iterated to agree with measured indices of refraction and unit-cell parameters. This composition also must agree with direct measurement of density and with partial or complete analysis of composition by another method. To attain consistency in index-of-refraction and unit-cell metrics, composition is altered in the structural formula by proposing $a_{\mathrm{i}}$ atoms per formula unit, finding the corresponding weight-fractions $w_{\mathrm{i}}$, and using the $k_{\mathrm{i}}$ values to iteratively minimize differences across the equality $n / \Sigma\left(k_{\mathrm{i}} w_{\mathrm{i}}\right)=\Sigma\left(a_{\mathrm{i}} \mathrm{AW}\right) / V \mathrm{~A}_{\mathrm{N}}$. This approach is rather interesting, because the equation is in essence a comparison of low-energy photon refraction (giving values of

TABLE 2. REFINED VALUES of $k$ FOR GARNET-GROUP MINERALS

\begin{tabular}{lccccc} 
Mineral & $k\left(\mathrm{Al}_{2} \mathrm{Si}_{3} \mathrm{O}_{12}\right)$ & $k\left(\mathrm{Mg}^{2+}\right)$ & $k\left(\mathrm{Fe}^{2+}\right)$ & $k\left(\mathrm{Mn}^{2+}\right)$ & $k\left(\mathrm{Ca}^{2+}\right)$ \\
\hline Pyrope & 0.4241 & 0.7420 & 0.4219 & 0.4378 & 0.6358 \\
Grossular & 0.4266 & 0.7192 & 0.4204 & 0.4365 & 0.6353 \\
Spessartine & 0.4268 & 0.7236 & 0.4181 & 0.4352 & 0.6420 \\
Almandine & 0.4253 & 0.7333 & 0.4207 & 0.4383 & 0.6363
\end{tabular}

Units: $\mathrm{cm}^{3} / \mathrm{g}$. Standard deviation: $\pm 0,0001$ 
$n$ ) and high-energy photon reflection (giving cell edge and $V$ ).

\section{Conclusions}

If light is refracted to a specific degree by each ion of a mineral, as shown in this analysis, it is not possible that the refracting medium be homogeneous. The staggered array of ions in a close-packed structure ensures a winding non-linear path of light. Any measured reduction of velocity from entry to exit points is not associated with reduction in wavelength, but the winding optical path $(l)$ is increased over the linear geometric path $(d)$ by $l=n d$. Now a case is made for a return to the Newtonian view of light, with refracting particles acting as a probe of atomic structure. Force acts on a local photon to give continuous refraction toward a specific level of energy (Teertstra 2003). According to Maxwell, light is electromagnetic in composition (Iksander 1992), and the refraction of light takes place mainly by the action of electrical charge perpendicular to the direction of propagation. In Einstein's view (Arons \& Peppard 1965), the electrical charge of proton and electron remains invariant, but the electric binding energy $\mathrm{E}$ is expressed as change of rest mass by $\boldsymbol{m}=E / c^{2}$. Refraction is thus not directly affected by inertial atomic mass, but each atom has a specific contribution of electrical refractive volume (Table 3 ), radius and atomic mass, giving the $n, V$ and $D$ of a mineral, respectively.

The advantage of optical analysis is that it places close constraints on the structural formula of a mineral. Uncertainty in the structural formula of a mineral can result from incomplete or inaccurate analysis, lack of determination of valence, and uncertain distributions of elements among crystallographic sites. On the basis of composition alone, the structural formula of a mineral commonly remains ambiguous; garnet with ${ }^{\mathrm{VI}} \mathrm{Al}$ and possible ${ }^{\mathrm{IV}} \mathrm{Al}$ is an example. Deer et al. (1992) relied on site preferences to distribute cations among various sites in the structure and looked for a sensible formula to substantiate the choices. The result is a reasonable range of valence states and possible states of cation order. But these proposed states are further constrained by measurement of $n$ and $a$ or $D$, by optical analysis. For each structure-type, distinct $k$-values are found with respect to ion valence and coordination number (Eggleton 1991). Most significantly, optical analysis constrains the

TABLE 3. IONIC REFRACTING VOLUMES V,

\begin{tabular}{lcccc}
\hline Mineral & $\mathrm{Mg}^{2+}$ & $\mathrm{Fe}^{2+}$ & $\mathrm{Mn}^{2+}$ & $\mathrm{Ca}^{2+}$ \\
\hline Pyrope & 0.02995 & 0.03913 & 0.03994 & 0.04232 \\
Grossular & 0.02903 & 0.03899 & 0.03982 & 0.04228 \\
Spessartine & 0.02920 & 0.03877 & 0.03970 & 0.04235 \\
Almandine & 0.02960 & 0.03901 & 0.03998 & 0.04273
\end{tabular}

Units: $\mathrm{nm}^{3} \pm 0.00001$ concentrations of light elements that cannot be determined by electron microprobe, namely $\mathrm{H}, \mathrm{Li}, \mathrm{Be}, \mathrm{B}, \mathrm{C}$, $\mathrm{N}$ and especially $\mathrm{O}$.

The index of refraction of a mineral can be explained exactly by the use of $k_{\text {ion }}$ values of refractivity with linear variation across series (Table 2). A chemical composition need not be complete for application of optical analysis, as the optical analysis quantifies the contribution of non-analyzed components (Fig. 3). Furthermore, the vector-additive qualities of the Gladstone-Dale relation allow examination of the contributions of specific structural components to the index of refraction. Although the example of $X_{3} \mathrm{Al}_{2} \mathrm{Si}_{3} \mathrm{O}_{12}$ garnets isolated the $k$ values of $X$ cations in quaternary solid-solution and the $\mathrm{Al}_{2} \mathrm{Si}_{3} \mathrm{O}_{12}$ component, ions need not substitute at the same site in order to find a solution.

The net change in index of refraction is not solely due to compositional change at the $X$ site, but also results from structural changes that are induced in the $\mathrm{Al}_{2} \mathrm{Si}_{3} \mathrm{O}_{12}$ unit; as a result, the $k\left(\mathrm{Al}_{2} \mathrm{Si}_{3} \mathrm{O}_{12}\right)$ changes. The refractive power of an $X$ cation increases with increasing proximity of $\mathrm{O}^{2-}$, and $k\left(\mathrm{O}^{2-}\right)$ also increases; conversely, ions of like charge act to decrease the $k$ values. The refractive power of an ion is directly indicated by the refracting volume $V_{\mathrm{r}}$ (Table 3 ); it increases with increasing radius of the cation in the sequence $\mathrm{Mg}$ $<\mathrm{Fe}<\mathrm{Mn}<\mathrm{Ca}$. A photon in $2.15 \mathrm{eV}$ yellow light refracts along a specific arc about the nucleus of a cation, depending on the radial distance of $2+$ charge extending from the noble gas core of the cation. In summary, it is reasonable to consider a local photon as an intact refracting probe of atomic structure and to develop methods for refracted-photon analysis of a crystal structure (Teertstra 2003).

\section{ACKNOWLEDGEMENTS}

Associate Editor Mickey E. Gunter provided numerous comments that extended the range of the manuscript. Referee Brian Cooper encouraged a re-organization of topics that considerably improved the manuscript. I thank the master of optical mineralogy, F. Donald Bloss, for his wise and detailed comments on the manuscript and for providing a sound basis for descriptive optical mineralogy through decades of careful research. I thank Robert F. Martin for his patient and meticulous annotation of the text.

\section{REFERENCES}

AlLEN, R.D. (1956): A new equation relating index of refraction and specific gravity. Am. Mineral. 41, 245-257.

Arons, A.B. \& Peppard, M.B. (1965): Einstein's proposal of the photon concept - a translation of the Annalen der Physik paper of 1905. Am. J. Phys. 33, 367-372. 
BAIERLEIN, R. (1992): Newton to Einstein: the Trail of Light. Cambridge University Press, Cambridge, U.K.

BLoss, F.D. (1952): Relationship between density and composition in mol per cent for some solid solution series. Am. Mineral. 37, 966-981.

Gunter, M., Su, Shu-Chun \& Wolfe, H.E. (1983): Gladstone-Dale constants: a new approach. Can. Mineral. 21, 93-99.

DeER, W.A., HowIE, R.A. \& Zussman, J. (1992): An Introduction to the Rock-Forming Minerals. Longman Scientific \& Technical, London, U.K.

EgGLETON, R.A. (1991): Gladstone-Dale constants for the major elements in silicates: coordination number, polarizability and the Lorenz-Lorentz relation. Can. Mineral. 29, 525-532.

Gladstone, J.H. \& DALE, T.P. (1864): Researches on the refraction, dispersion and sensitiveness of liquids. Phil. Trans. R. Soc. London 153, 317-343.

Herbstein, F.H. (2000): How precise are measurements of unit-cell dimensions from single crystals? Acta Crystallogr. B56, 547-557.

IKSANDER, M.F. (1992): Electromagnetic Fields \& Waves. Prentice-Hall, New York, N.Y.

JAFFE, H.W. (1956): Application of the rule of Gladstone and Dale to minerals. Am. Mineral. 41, 757-777.
(1988): Crystal Chemistry and Refractivity. Cambridge University Press, Cambridge, U.K.

LARSEN, E.S. (1921): The microscopic determination of the non-opaque minerals. U.S. Geol. Surv., Bull. 679.

MANDARINO, J.A. (1976): The Gladstone-Dale relationship. I. Derivation of new constants. Can. Mineral. 14, 498-502.

Nikogosyan, D.N. (1997): Properties of Optical and LaserRelated Materials: a Handbook. John Wiley \& Sons, New York, N.Y.

NovaK, G.A. \& GiBbs, G.V. (1971): The crystal chemistry of the silicate garnets. Am. Mineral. 56, 791-825.

SKINNER, B.J. (1956): Physical properties of end-members of the garnet group. Am. Mineral. 41, 428-436.

Teertstra, D.K. (2003): Polarized Light Optics: The New Physics of the Photon. Euclid Geometrics, Kitchener, Ontario [reviewed in Can. Mineral. 41, 1295-1296].

HAwTHORNe, F.C. \& ČERNÝ, P. (1998): Identification of normal and anomalous compositions of minerals by electron-microprobe analysis: K-rich feldspar as a case study. Can. Mineral. 36, 87-95.

Zoltai, T. \& Stout, J.H. (1984): Mineralogy: Concepts and Principles. Burgess, Minneapolis, Minnesota.

Received May 7, 2004, revised manuscript accepted November 15, 2004 